\title{
INFORME DE LA \\ COMISIÓN NACIONAL SOBRE PRISIÓN POLÍTICA Y TORTURA, Y RESPUESTAS INSTITUCIONALES*
}

Estudios Públicos recoge en las páginas que siguen textos del informe de la Comisión Nacional sobre Prisión Política y Tortura, incluido el prólogo del Presidente de la República. Se reproducen también aquí las declaraciones y reacciones que provocó el Informe en las distintas ramas de las Fuerzas Armadas y de Orden, así como en la judicatura.

Como en ocasiones anteriores - Informe de la Comisión Nacional de Verdad y Reconciliación (1991), Acuerdo de la Mesa de Diálogo sobre Derechos Humanos (2000) y la propuesta de derechos humanos del Presidente Lagos de agosto del 2003 - su publicación contribuye a dejar memoria y llama a reflexionar acerca de las graves y sistemáticas violaciones a los derechos humanos ocurridas durante el régimen militar.

Arturo Fontaine Talavera

Director

* Para acceder a otros documentos y artículos de Estudios Públicos sobre la historia política de Chile y la cuestión de los derechos humanos, véase www.cepchile.cl 


\section{ÍNDICE}

Introducción

\section{A. Informe de la Comisión Nacional sobre Prisión Política y Tortura (extractos)}

Prólogo de S.E. el Presidente de la República.

"Para nunca más vivirlo, nunca más negarlo".

Capítulo III: Contexto.

Capítulo IV: Prisión política y tortura, período por período.

Capítulo V: Métodos de tortura.

Capítulo VI: Recintos de detención.

Capítulo VII: Perfil de las víctimas.

Capítulo VIII: Consecuencias de la prisión política y tortura.

Capítulo IX: Propuestas de reparación.

\section{B. Respuestas institucionales (por orden cronológico)}

"Ejército de Chile: El Fin de una Visión", noviembre 3, 2004.

General Juan Emilio Cheyre, Comandante en Jefe del Ejército.

Declaración, noviembre 13, 2004.

Policía de Investigaciones de Chile.

Declaración, noviembre 30, 2004.

Armada de Chile.

Comunicado Oficial, noviembre 30, 2004.

Carabineros de Chile.

Declaración, diciembre 1, 2004.

Fuerza Aérea de Chile.

Discurso (en seminario organizado por el Ejército de Chile, diciembre 7, 2004).

General Juan Emilio Cheyre, Comandante en Jefe del Ejército.

Declaración, diciembre 9, 2004.

Corte Suprema.

Declaración, diciembre 14, 2004.

Asociación Nacional de Magistrados del Poder Judicial de Chile. 


\section{INTRODUCCIÓN ${ }^{1}$}

El 12 de agosto de 2003, el Presidente Ricardo Lagos presentó al país su propuesta para encarar el problema aún no resuelto de las violaciones a los derechos humanos en Chile. Este documento fue titulado "No Hay Mañana Sin Ayer" y entre sus propuestas figuraba el establecimiento de una Comisión que "establezca de manera rigurosa una lista de personas que hayan sufrido privación de libertad y tortura por razones políticas"2. A este fin, el documento precisó que el propósito de la Comisión sería "determinar quiénes son los chilenos y chilenas que pasaron por esta experiencia, se creará por decreto supremo una comisión responsable de extender un certificado que acredite esta calidad. Tal certificado permitirá a las personas que lo poseen y que no han recibido otra forma de reparación, una indemnización austera y simbólica que determinará el ejecutivo. Esta Comisión, en su metodología de trabajo, tendrá las mismas características de la Comisión Rettig para garantizar la plena privacidad de su labor."

La propuesta se materializó tres meses después. Por Decreto Supremo $\mathrm{N}^{\circ} 1.040$ de Interior, publicado en el Diario Oficial el 11 de noviembre de 2003, fue creada la "Comisión Nacional sobre Prisión Política y Tortura", como órgano asesor del Presidente de la República. Entre los considerandos que anteceden a esta norma, se señala: "Que cualquier intento de solución del problema de los derechos humanos en Chile obliga a dar una mirada global a las violaciones de los derechos esenciales de la persona humana y a reconocer a las víctimas de dichas violaciones; que muchas de esas personas no han sido hasta la fecha reconocidas en su carácter de víctimas de la represión, ni han recibido reparación alguna por parte del Estado; que sólo en la medida que se esclarezca completamente la verdad, se reconozca a sus víctimas y se repare el injusto mal causado, el país podrá avanzar en forma efectiva por el camino de la reconciliación y el reencuentro; que la experiencia de la Comisión Nacional de Verdad y Reconciliación [Comisión Rettig] y de la denominada mesa de Diálogo demuestran que es posible alcanzar crecientes grados de verdad...".

A la Comisión se le encomendó dos tareas básicas. Primero, "determinar, de acuerdo a los antecedentes que se presenten, quiénes son las personas que sufrieron privación de libertad y torturas por razones políti-

${ }^{1}$ Las citas del Informe y de la Nómina de Personas Reconocidas como Víctimas hechas en esta introducción, provienen del texto publicado en formato PDF en www.comisionprisionpoliticaytortura.cl Los números que acompañan a las citas refieren a las páginas de esos textos.

${ }^{2}$ El texto completo de la propuesta presidencial "No Hay Mañana sin Ayer" se encuentra publicado en Estudios Públicos, 92 (primavera 2003), pp. 314-333. 
cas, por actos de agentes del Estado o de personas a su servicio, en el período comprendido entre el 11 de septiembre de 1973 y el 10 de marzo de 1990”. Segundo, "proponer al Presidente de la República las condiciones, características, formas y modos de las medidas de reparación, austeras y simbólicas, que podrán otorgarse a las personas que, reconocidas como prisioneros políticos o torturados, no hubieren recibido hasta la fecha otro beneficio de carácter reparatorio derivado de tal calidad."

Los miembros de la Comisión fueron: Monseñor Sergio Valech Aldunate, quien la presidió; María Luisa Sepúlveda Edwards, su vicepresidenta ejecutiva, Miguel Luis Amunátegui Monckeberg, Luciano Fouillioux Fernández, José Antonio Gómez Urrutia, Elizabeth Lira Kornfeld, Lucas Sierra Iribarren y Álvaro Varela Walker.

De acuerdo al citado decreto supremo, para que una persona pudiera ser calificada como "víctima" por la comisión debían concurrir los siguientes requisitos copulativos:

- La privación de libertad o la tortura, o ambas si fuera el caso, debían haber obedecido a razones políticas;

- Los victimarios debían ser agentes del Estado o personas a su servicio, entendiéndose por tales a aquellos particulares que, sin tener calidad de agentes del Estado, actuaban con conocimiento, tolerancia, aquiescencia o en connivencia con éstos, sin que se precise una relación formal o de orden contractual, y

- Los hechos debían haber acaecido entre el 11 de septiembre de 1973 y el 10 de marzo de 1990.

No pudieron ser calificadas como víctimas, pues el decreto las excluyó de antemano, "las personas privadas de libertad en manifestaciones públicas, que fueron puestas a disposición de los tribunales de policía local o de algún tribunal del crimen por delitos comunes y luego condenadas por estos delitos". Tampoco se incluyeron las personas que fueron objeto de "retenciones" temporales efectuadas durante allanamientos masivos, operaciones "peineta", u otra forma similar de control colectivo o indiscriminado de la población. Por otro lado, a la luz del Decreto Supremo $\mathrm{N}^{\circ} 355$ de 1990, de los ministerios de Interior y Justicia, que creó la Comisión Rettig, y del citado Decreto Supremo N ${ }^{\circ} 1.040$ de 2003, la Comisión estimó que los actos de privación de libertad o tortura por razones políticas que hubiesen ocasionado la muerte de la persona que los sufrió, quedaban excluidos de su mandato, pues fueron objeto, precisamente, de la Comisión Rettig. Por último, la Comisión consideró que las personas que sufrieron prisión política y tortura en el período que cubrió su mandato, pero que fallecieron 
antes de la recepción de antecedentes por parte de la Comisión, podrían ser calificadas como "víctimas" en la medida que sus familiares directos presentaran su caso y lo acreditaran.

En cuanto a la competencia y procedimiento de la Comisión, el Decreto Supremo $\mathrm{N}^{\circ} 1.040$ estableció una precisión fundamental: "En el cumplimiento de su objeto, la Comisión no podrá, de manera alguna, asumir funciones de carácter jurisdiccional $\mathrm{y}$, en consecuencia, no podrá pronunciarse sobre la responsabilidad que con arreglo a la ley pudiera caber a personas individuales por los hechos de que haya tomado conocimiento." La Comisión, por tanto, no fue un tribunal, sino un órgano asesor del Presidente de la República.

Lo anterior explica el hecho de que no se haya pretendido que ella se sometiera a las exigencias básicas del debido proceso, como por ejemplo, la bilateralidad de la audiencia. Esto justifica su deber de no pronunciarse sobre responsabilidades individuales e, incluso, de omitir los nombres de personas determinadas que puedan aparecer envueltas como victimarios en los hechos que ella ha conocido. Asimismo, este carácter no jurisdiccional tiene consecuencias sobre el valor probatorio de sus conclusiones. Obviamente, éstas no hacen "plena prueba", no, al menos, en el sentido más judicial de la expresión. El informe, por tanto, no fue concebido para ser presentado alguna vez como medio de prueba en algún determinado juicio, sino que más bien como antecedente para la discusión pública.

Según indica el Informe, para confeccionar este antecedente la Comisión siguió el modelo de la Comisión Rettig e intentó "adquirir convicción moral" para calificar los hechos que se le presentaron. Los hechos a calificar fueron la calidad de víctima de prisión política y de tortura. Así lo describe el informe:

"Siguiendo la metodología instaurada por la Comisión Rettig, la Comisión entendió por calificación el proceso colegiado de evaluación de los antecedentes permitieran adquirir convicción moral respecto de la calidad de preso o torturado por razones políticas, o ambas. Esto, en términos tales que ameriten su reconocimiento oficial como tal o se deseche la petición.” (Informe, pp. 45-46.)

Si bien el criterio de "convicción moral" para calificar los hechos fue un punto de semejanza entre la Comisión Rettig y esta Comisión, hubo también un punto de significativa diferencia: el carácter de los hechos que les correspondió calificar. La Comisión Rettig tuvo por objeto determinar las personas ejecutadas y las que fueron desaparecidas, por agentes del Estado, entre 1973 y 1990. Esta Comisión, en cambio, debió calificar las personas que sufrieron prisión política y, además, tortura. Aparte de una enorme diferencia en el número de casos que les correspondió conocer 
- la Comisión Rettig conoció la décima parte de los casos conocidos por ésta-, la forma de acreditar los hechos fue también diferente. La prueba de las ejecuciones cuyas víctimas debió calificar la Comisión Rettig no fue fácil, pues, por regla general, quedó poco rastro de ellas. Como se comprenderá, la prueba de las desapariciones fue aún más difícil. Lo dramático de éstas es, precisamente, el hecho de que no hay rastro.

Sobre la prisión política, en cambio, hay más rastro. Por lo pronto, y a diferencia de la Comisión Rettig, aquí las víctimas, en su inmensa mayoría, están vivas para dar testimonio. Además, una parte importante de los casos calificados por esta Comisión tuvieron el respaldo de pruebas documentales. Como puntualiza este informe, y a fin de ir construyendo una base de datos con toda la información disponible, la Comisión "celebró acuerdos de cooperación y entrega de información con la Fundación de Archivos de la Vicaría de la Solidaridad, la Fundación de Ayuda Social de Iglesias Cristianas (FASIC), el Comité de Defensa de los Derechos del Pueblo (CODEPU) y la Fundación para la Protección de la Infancia Dañada por los Estados de Emergencia (PIDEE). Se realizó también un convenio con la Universidad Alberto Hurtado, mediante el cual fue posible el trabajo de un grupo de alumnos que investigó los informes de la Organización Internacional del Trabajo, OIT, rescatando de esa fuente los nombres de personas detenidas, en su mayoría dirigentes sindicales, respecto de las cuales se recurrió a esta organización en el momento en que sus derechos eran vulnerados. Este grupo investigó, con el mismo objetivo, en los archivos de prensa de la época que custodia la Fundación de Documentación y Archivo de la Vicaría de la Solidaridad, y entregó en ambos casos los registros en archivos computacionales que fueron integrados a la base de datos de esta Comisión. Mediante la realización de convenios fue posible también acceder a los archivos del Obispado de San Felipe, del Obispado de Talca, del Obispado de Copiapó, del Obispado de Temuco y del Departamento de la Pastoral Obrera de Concepción, todos los cuales fueron instrumentos de gran importancia para obtener documentación de respaldo en numerosos casos y validar en fuentes confiables la que había sido presentada. Se utilizaron con este fin complementario los siguientes registros: las relaciones que aparecen en los numerosos libros publicados en el período; dos listados de detenidos elaborados aparentemente por el Ejército, que contenían nombres de más de 12.000 detenidos en diversos recintos de dicha rama y de la Armada, en noviembre y diciembre de 1973; listados de Gendarmería de detenidos en distintas unidades penales del país por razones políticas y las respuestas que este servicio del Estado entregó a numerosas consultas hechas por esta Comisión; listas entregadas por el Archivo Nacional de los libros de ingreso a la Cárcel Pública de prisioneros de 
guerra; relación de los ingresos de recursos de amparo a la Corte de Apelaciones de Santiago durante los años 1973 a 1976; información entregada por el Servicio de Registro Civil e Identificación en respuesta a consultas hechas por la Comisión; información sistematizada del Informe Nacional de Verdad y Reconciliación [Informe Rettig] y de la Comisión Nacional de Reparación y Reconciliación; información de entidades estatales, como el Ministerio del Interior, Ministerio de Justicia, Ministerio de Defensa y de las Fuerzas Armadas y de Orden; información solicitada a distintos servicios y empresas del Estado, como la Tesorería General de la República, el Servicio de Aduanas, la Empresa Nacional de Minería ENAMI, la Corporación del Cobre (CODELCO), Instituto de Desarrollo Agropecuario, INDAP, Servicio de Impuestos Internos, entre otras." (Informe, pp. 30 y 31.)

Un criterio clave a la hora de calificar la prisión política fue la "motivación política" de la privación de libertad. Al respecto, señala el informe: "La motivación política no siempre es evidente y, de hecho, la actividad represiva siempre buscó respaldo en la supuesta defensa de la seguridad del Estado, del orden público, de la lucha contra el terrorismo, etc. Para discernir la presencia de tal motivación se pueden considerar los siguientes factores:

a) La existencia de la motivación política como fundamento único del acto represivo se reconoce porque deja de haber delito cuando se omite la motivación política de la conducta del imputado. Esto se refiere a los casos en que la conducta sancionada es enteramente de naturaleza política, como las acciones penadas como consecuencia de la prescripción del quehacer político o la pertenencia a partidos declarados asociaciones ilícitas por la mera doctrina a que adhieren, como ocurre con el Decreto Ley $\mathrm{N}^{\circ}$ 77, que declaró ilícitos a los partidos políticos pertenecientes a la Unidad Popular. Dentro de este concepto se consideran todas las normas jurídicas dictadas en contravención de las normas y principios del derecho internacional de derechos humanos, que como-normas jurídicas penalizaron conductas propias del ejercicio de un derecho reconocido por el derecho internacional, o establecieron medidas punitivas en contra de personas a causa de su identidad.

b) La existencia de medidas privativas de libertad sin juicio y sin fundamento, como las detenciones administrativas o la aplicación de medidas restrictivas o privativas de libertad una vez cumplidas las condenas, en virtud de las atribuciones de los estados de excepción constitucional. Ello es particularmente claro dada la extensión temporal de la vigencia de dichos estados de excepción y la falta de justificación y de control democrático de su vigencia y renovación. 
c) La aplicación de normas jurídicas en forma arbitraria o con claros fines de represión política de mayor rigor en el juzgamiento de hechos, impuestas en forma arbitraria o con claros fines de represión política, como la ampliación de las penas o las restricciones en el derecho a defensa impuestas por el tiempo de guerra sin existir las hipótesis de hecho que justifica tal declaración y sin el consiguiente reconocimiento de las garantías establecidas en los Convenios de Ginebra para los acusados de delitos supuestamente considerados en dicha categoría, o la imposición del fuero militar para juzgar delitos que carecen de tal carácter, lo que se traduce en extensiones de los períodos de detención sin requerirse la presentación de los detenidos ante los tribunales, extensiones de los períodos de incomunicación y otras limitaciones al derecho a defensa y a las garantías del debido proceso. El juzgamiento de hechos bajo estas condiciones o en virtud de normas especiales, como la Ley de Seguridad Interior del Estado, contiene claramente una motivación política.

d) También existe motivación política en la detención y juzgamiento de delitos que constituyen hechos delictivos sancionados por cualquier legislación ordinaria de un país, que fueron cometidos con la intención de derrocar al régimen o impulsar cambios políticos. Si bien en estos casos la privación de libertad no es ilegítima per se, debe velarse por el cumplimiento de garantías del debido proceso en el juzgamiento de los hechos y por que no se apliquen torturas a los imputados." (Informe, pp. 24 y 25.)

A diferencia de la prisión política, de la tortura hay menos rastro. Por regla general, no hay secuelas visibles tras los años transcurridos desde los hechos conocidos por la Comisión y, obviamente, no hay prueba documental de ella. Indica el Informe: "No ha sido posible disponer de la acreditación de la tortura mediante informes médicos u otras formas de constatación de las lesiones o secuelas. Dado el contexto en que ocurrieron los hechos, particularmente en los primeros años del régimen militar, muy pocas personas recibieron atención de salud con el objeto de constatar las torturas y algunas permanecieron detenidas por largo tiempo luego de que ellas les fueran inflingidas, haciendo prácticamente imposible certificarlas. Finalmente, tampoco ha sido posible calificar las situaciones de tortura de acuerdo a su gravedad. Luego de treinta años no es posible evaluar lo padecido por una persona de acuerdo a la calificación de su relato o escudriñar en sus recuerdos sin generar una nueva victimización. Por ello, reconociendo el sufrimiento de las personas, la Comisión ha estimado razonable definir una categoría común de víctimas." (Informe, "Nómina de personas reconocidas como víctimas", pp. 8-9.) De este modo, la Comisión no pretendió probar la tortura respecto de cada persona en particular, pero 
por la inmensa cantidad de testimonios coincidentes sobre métodos, recintos, organismos, períodos y otras circunstancias, sí pudo convencerse de que fue una práctica con un carácter sistemático y de que no hay razones para dudar de los presos políticos que la denuncian de manera coherente con este carácter.

La Comisión trabajó con una definición operativa de "tortura", extraída de dos documentos del derecho internacional: La Convención contra la Tortura y otros Tratos o Penas Crueles, Inhumanos o Degradantes, de la ONU, y la Convención Interamericana para Prevenir y Sancionar la Tortura, de la OEA ${ }^{3}$. Dice esa definición: "Constituye tortura todo acto por el cual se haya infligido intencionadamente a una persona dolores o sufrimientos graves, ya sean físicos o mentales, con el fin de obtener de ella o de un tercero información o una confesión, castigarla por un acto que haya cometido o se sospeche que ha cometido, intimidar o coaccionar a esa persona u otras, anular su personalidad o disminuir su capacidad física o mental, o por razones basadas en cualquier tipo de discriminación. Siempre y cuando dichos dolores o sufrimientos se hayan cometido por un agente del Estado u otra persona a su servicio, o que actúe bajo su instigación, o con su consentimiento o aquiescencia." (Informe, p. 19.)

Desde un punto de vista orgánico, la Comisión tuvo dos dimensiones distintas, pero complementarias: la Comisión propiamente tal, cuya tarea fue conocer y decidir los casos que se presentaron; y la vicepresidencia ejecutiva, integrada por equipos de profesionales, técnicos y administrativos, que sirvió de estructura operativa y de apoyo a la Comisión. La vicepresidencia ejecutiva se dividió en cuatro áreas y dos unidades de apoyo. Entre las primeras: atención de público, información e investigación documental, calificación y administración y finanzas. Entre las segundas: unidad de procesamiento y archivo, y unidad de apoyo informático.

La Comisión tuvo su sede en Santiago, pero el trabajo se extendió por el país y el extranjero. Señala el Informe: "En regiones se atendió en 42 gobernaciones, con profesionales de los equipos locales designados especialmente para atender las tareas de la Comisión en cada provincia. En las 13 gobernaciones de mayor población se realizaron contrataciones de profesionales destinados a asumir y reforzar el trabajo local. Durante todo el período de recepción de antecedentes, profesionales del equipo central se desplazaron a regiones para apoyar directamente la atención de público, efectuando en forma extraordinaria 160 visitas a 106 localidades apartadas o que no eran sede de gobernación. Para aquellas víctimas que en la actualidad residen en el extranjero se estableció una coordinación con el Minis-

${ }^{3}$ La promulgación de ambas convenciones por parte de Chile se publicó el 26-11-88 en el Diario Oficial. 
terio de Relaciones Exteriores, a fin de realizar la recepción de antecedentes a través de los consulados de Chile en el exterior." (Informe, p. 28)

Desde un punto de vista funcional, el trabajo de la Comisión tuvo tres etapas. Primero, recepción de antecedentes en todo el país y en el extranjero; segundo, análisis de los casos y, tercero, calificación de los casos. La primera etapa consistió en la entrega de una ficha por parte de cada declarante, junto a todos sus antecedentes, y una entrevista personal. Esta presentación debió ser hecha en forma personal y voluntaria por cada interesado. Sólo en casos excepcionales como, por ejemplo, el de personas ya muertas o probadamente impedidas de concurrir a la Comisión, se aceptó su representación por familiares cercanos. La segunda etapa, como señala el Informe, estuvo compuesta por las siguientes tareas: "validar la información en fuentes confiables; realizar investigación documental; solicitar referencias a organismos de derechos humanos; solicitar referencias a organizaciones de víctimas; solicitar referencias a organismos públicos; investigar las referencias y testigos; validar mediante investigación en base de datos disponibles, realizar una segunda entrevista si los pasos anteriores hubieren sido insuficientes" (Informe, p. 41).

Realizadas estas tareas, fue posible avanzar algunas de las siguientes conclusiones: "La privación de libertad o tortura por razones políticas resultó suficientemente demostrada; pudo haber existido privación de libertad o tortura, pero resultó imposible obtener elementos de validación; si bien pudo haber habido una violación de derechos humanos, no existió privación de libertad o tortura por motivos políticos, cometida por agentes del Estado, en el período y con las características comprendidas en el mandato de la Comisión; el caso está fuera del mandato institucional" (Informe, p. 43) Esta información fue sintetizada mediante las siguientes categorías tentativas: "Precalifica: Incluía aquellas presentaciones que contenían suficientes antecedentes para proceder a su precalificación, tanto por lo verosímil de la relación como por la acreditación documental que se acompañaba, y casos con antecedentes documentales parciales, pero cuyo contexto y los hechos relatados permitían formarse convicción moral respecto de su veracidad. No precalifica: Se trataba de aquellas presentaciones claramente fuera de mandato, casos de violaciones a los derechos humanos con resultado de muerte, allanamientos sin detención, exilio, amedrentamientos, detenciones en manifestaciones de protesta por Carabineros y sin privación de libertad ni denuncia judicial de torturas, o por estar fuera del límite temporal, etc. Con antecedentes por definir conforme a mandato: Incluía aquellas denuncias que contaban con suficientes antecedentes de respaldo o eran coherentes en su relato, pero presentaban dudas respecto de su inclusión en el mandato." (Informe, p. 43.) 
Con toda esta información a la vista, se pasaba a la tercera y última etapa, en la cual la Comisión decidía finalmente sobre cada caso, formándose convicción moral respecto de él, según se explicó más arriba. Si la calificación resultaba positiva, la Comisión declaraba en cada caso la "condición de víctima de prisión o tortura por razones políticas". De los 35.868 casos presentados a la Comisión, 27.255 merecieron esta declaración (sobre un total de 33.221 detenciones, ya que muchas personas fueron detenidas más de una vez).

\section{El Informe}

En el cumplimiento de su mandato, la Comisión produjo un Informe que fue entregado al Presidente de la República el 10 de noviembre de 2004, y éste lo dio a conocer al país el 28 del mismo mes ${ }^{4}$. El Informe tiene dos partes. La primera está compuesta por diez capítulos y la segunda por la nómina de las 27.255 personas calificadas como víctimas. En la primera parte, el Capítulo I contiene una "Presentación", y el Capítulo II, "Funcionamiento de la Comisión", que se refiere a diversos aspectos orgánicos y metodológicos de ella, en los términos sintetizados más arriba. Los capítulos siguientes contienen la sustancia del trabajo de la Comisión, según el orden y la descripción que aparece en las páginas 87 y 88 del Informe.

Capítulo III: Contexto. "Descripción general del proceso de instalación del poder y concentración de éste al iniciarse el régimen militar, con referencia a los estados de excepción constitucional y las normas dictadas para la represión política, el papel que desempeñó el Poder Judicial, el funcionamiento de los tribunales de guerra, el papel que desempeñó la prensa, y las acciones de defensa y de denuncia que se llevaron a cabo en Chile y en el exterior."

Capítulo IV: Prisión política y tortura, período por período. "Explicación de la forma como operó la prisión política y la tortura en tres períodos: septiembre a diciembre de 1973, como la etapa de las detenciones masivas y el uso de centros de detención públicos y de gran capacidad; 1974 a 1977, período de predominio de la DINA y de mayor selectividad; 1978 a 1990, etapa marcada por la actuación de la CNI, la irrupción de un movimiento de oposición democrática y la aparición de grupos organizados de oposición armada."

\footnotetext{
${ }^{4}$ El texto del discurso "Para Nunca Más Vivirlo, Nunca Más Negarlo", con que el Presidente de la República dio a conocer el Informe al país (Prólogo del Informe), se incluye en este número de Estudios Públicos.
} 
Capítulo V: Métodos de tortura: definiciones y testimonios. "Descripción de los diferentes métodos que se aplicaron, ejemplificados con extractos de testimonios directos de las propias víctimas. Se incluye un apartado acerca de la violencia sexual en contra de mujeres."

Capítulo VI: Recintos de detención. "Itinerario de la prisión en cada región, con referencia a los recintos por los que usualmente pasaban las personas y el trato que allá recibían los detenidos. Descripción de los recintos de detención más importantes de cada región, sus características y régimen interno, y enumeración de los restantes recintos en donde permanecieron prisioneros políticos, indicando la época en la que funcionaron como tales."

Capítulo VII: Perfil de las víctimas. "Descripción de las características de las víctimas: edad, sexo, ocupación, nivel de compromiso político o social, etc., y comparación de su situación al momento de la detención con su estado actual. Este capítulo y el anterior sirven de orientación para las propuestas de medidas de reparación, al identificar las necesidades más frecuentes mencionadas por las víctimas."

Capítulo VIII: Consecuencias de la prisión política y la tortura. "Explicación de las secuelas sufridas por las víctimas de prisión política y tortura en los planos físico y psicológico, a partir de la propia percepción de las personas 30 años después de ocurridos los hechos."

Capítulo IX: Propuestas de reparación. "Propuestas de criterios de reparación que se presentan al Presidente de la República, que son en los ámbitos jurídico, económico, moral, de salud y social. Se incluyen sugerencias de medidas en beneficio directo de las víctimas, así como medidas de prevención y promoción de los derechos humanos, gestos simbólicos de reparación y encuentro en el nivel social, y acciones destinadas al reconocimiento de la memoria. En materia social se recomiendan medidas relativas a vivienda, educación y exención del servicio militar obligatorio."

\section{Capítulo X: "Palabras finales".}

A continuación se reproducen el Prólogo del Presidente de la República y extractos de los capítulos recién mencionados, con excepción del último ("Palabras finales"). Luego, en la segunda parte de este documento, se incluyen las reacciones que provocó el Informe en las siguientes instituciones: Corte Suprema, Ejército, Armada, Fuerza Aérea, Carabineros, Investigaciones y Asociación Nacional de Magistrados de Chile.

\section{Lucas Sierra ${ }^{5}$.}

${ }^{5}$ Abogado e Investigador del Centro de Estudios Públicos (CEP). Miembro de la Comisión Nacional sobre Prisión Política y Tortura. 